\section{IJDMT}

(C) I A E M E

\title{
OPTIMIZATION OF PROCESS PARAMETERS IN DRY AND WET MACHINING OF TI-6AL-4V ELI USING TAGUCHI METHOD
}

\author{
R. DILLIBABU ${ }^{1}$ ， K. SIVASAKTHIVEL ${ }^{2}$, S. VINODHKUMAR ${ }^{3}$ \\ ${ }^{2}$ Research Scholar, Department of Industrial Engineering, Anna University, \\ Chennai-600025, India \\ ${ }^{3}$ PG Student, Department of Industrial Engineering, Anna University, \\ Chennai-600025, India \\ ${ }^{1}$ Associate Professor, Department of Industrial Engineering, Anna University, \\ Chennai-600025, India
}

\begin{abstract}
This paper reports the optimization of process parameters such as cutting speed $(\mathrm{m} / \mathrm{min})$, feed $(\mathrm{mm} / \mathrm{rev})$, depth of cut $(\mathrm{mm})$ and nose radius $(\mathrm{mm})$ in Dry and Wet machining using Taguchi method. Cutting fluids in machining operations help to remove the heat generated during cutting, to achieve better tool life and surface finish and to facilitate the flushing of chips. The machining without the use of any cutting fluid is becoming increasingly important due to concern regarding safety and environmental legalization. In addition it reduce $17 \%$ of manufacturing costs by not using cutting fluids. However in Dry machining operations, the friction and adhesion between chip and tool tend to be higher, which causes higher temperatures, higher wear rates and shorter tool life. This problem can overcome by using PVD coated TiAlN cutting tool. PVD - TiAlN coated carbide tools are used frequently in metal cutting process due to the higher hardness, wear resistance and chemical stability. In addition it improves tool life and machining performance.

The work piece material is Ti-6Al-4V ELI which is most widely used in bio-medical applications due to its high strength to weight ratio and exceptional corrosion resistance. The cost of titanium still remain high cost but longer service life counter balance the production cost. If the work piece material is machined by Dry machining the production cost will be reduced further without affecting the quality parameters .Experiment was conducted on Dry and Wet machining with identical cutting parameters. The main output monitored was the surface roughness.
\end{abstract}

Key Words: Dry Machining, Surface Roughness, Cutting Parameters, Titanium Alloy, PVD - Tialn Coated Carbide Tools, ANOVA. 
International Journal of Design and Manufacturing Technology (IJDMT), ISSN 0976 - 6995(Print), ISSN 0976 - 7002(Online) Volume 4, Issue 3, September - December (2013), ( I IAEME

\subsection{INTRODUCTION}

Productivity and Quality are integral components of organizations operational strategies. Productivity place an important role of both macro and micro levels. At micro level, firms use productivity as a performance measure to benchmark against best in class companies to identify best practices. Higher productivity means productivity more from a given amount of input. Quality has become an important part of management culture and virtual enterprise environments. Turning is the most widely used among all cutting processes. The increasing importance of turning operations is gaining new dimensions in the present industrial age, in which the growing competition calls for all the efforts to be directed towards the economical manufacture of machined parts and surface finish is the one of the most critical quality measures in mechanical products (1). The difficulties in optimization operations made the determination of ideal cutting parameters and important complex case (2). The determination of optimum cutting parameters plays an important role in reducing machining problems as tool destroy and wear (3). Srikanth and Kamala (4) studied the surface roughness optimization in Turning Operation by finding the optimum parameters (Speed, Feed and Depth of Cut) that minimize surface roughness. The formula used to calculate the surface roughness is as

$\mathrm{Ra}: \frac{1.0632 \times \mathrm{f}^{1.0198} \times \mathrm{d}^{0.0119} \times \mathrm{H}^{0.5234} \times \mathrm{r}^{0.1388}}{\mathrm{~V}^{0.229}}$

Where as

$\mathrm{Ra}$ - Surface Roughness $(\mu \mathrm{m})$

$\mathrm{f}$ - Feed Rate (mm/rev)

$\mathrm{d}-$ Depth of Cut (mm)

$\mathrm{H}$ - Material Hardness

$\mathrm{r}$ - Tool Radius (mm)

$\mathrm{v}-$ Cutting Speed $(\mathrm{mm} / \mathrm{min})$

Tool geometry place an important role in machining. It is mentioned that nose radius will affect the performance of the machining process. It is proved that high valves of the nose radius causes rough surface with high value of run out (6).

Machining of Titanium and its alloys differs from conventional turning of engineering materials like steel, in several key ways, mainly because the thermal conductivity of the materials is very low when compare to the steel $\left(\mathrm{K}_{T i}\right.$ is $7.3 \mathrm{~W} / \mathrm{mK}$ and $\mathrm{K}_{\text {steel }}$ is $50.7 \mathrm{~W} / \mathrm{mK}$ ). This low thermal conductivity results in high heat accumulation at the machining zone (shear zone) and heat dissipation is very less when compare to the conventional turning of steels.

Many literatures indicates that some cutting fluids such as the oil based and water based have been used successfully to prolong tool life in machining of Titanium and its Alloys. Recently dry cutting is becoming increasingly more popular as a means of reducing overhead costs while protecting the environment (5) . From environmental perspective, dry cutting can be characterized as green machining. Reducing or elimination when possible the use of cutting fluids in green machining means less waste dumped in landfills, less mist in the factory atmosphere, no residue on the chip which will be reflected in the reducing disposal and cleaning cost, cleaner workshop floors, and fewer dermatological problem for operators. Dry cutting is ecologically desirable and it will be considered as a necessity for manufacturing enterprises in the near future. 
International Journal of Design and Manufacturing Technology (IJDMT), ISSN 0976 - 6995(Print), ISSN 0976 - 7002(Online) Volume 4, Issue 3, September - December (2013), ( I IAEME

$\mathrm{Ti}-6 \mathrm{Al}-4 \mathrm{~V}$ ELI is the most widely used Titanium Alloy of the Alpha - Plus - Beta Class with extra low interstitials (ELI). This alloy is commonly used in medical implants where strength and corrosion resistance are most is important. PVD-TiAlN coated carbide tool is used frequently in metal cutting process due to their high hardness, wear resistance and chemical stability. Also, they offer higher benefits in terms of tool life and machining performance compare to other coated cutting tool variants. The improvement in the cutting performance is due to oxidation resistance of TiAlN properties at higher temperature (7).

In this study, nose radius has been taken into consideration along with cutting speed, feed rate and depth of cut. The fifth factor taken into consideration is the cutting environment. Machining is done under the two different environmental conditions - dry and wet.

\subsection{TAGUCHI METHOD}

Traditional experimental design methods are very complicated and difficult to use. Additionally, these methods require a large number of experiments when the number of process parameters increases. In order to minimize the number of tests required, Taguchi experimental design method, a powerful tool for designing high quality system, was developed by Taguchi. This method uses a special design of orthogonal arrays to study the entire parameters space with small number of experiment only. Taguchi recommends analyzing the mean response for each run in the inner array, and he also suggests analyzing variation using an appropriately chosen signal to noise ratio $(\mathrm{S} / \mathrm{N})$. Regardless of category of the performance characteristics, the lower $\mathrm{S} / \mathrm{N}$ ratio corresponds to a better performance. Therefore, the optimal level of the process parameters is the level with the lowest $\mathrm{S} / \mathrm{N}$ value. The statistical analysis of the data was performed by analysis of variance (ANOVA) to study the contribution of the factor and interactions and to explore the effects of each process on the observed value.

\subsection{DESIGN OF EXPERIMENTS}

In this study four machining parameters and one environment parameters were selected as control factors, and each machining parameter was designed to have three levels, denoted L1, L2 and L3 and environment parameters was designed to have two levels L1 and L2.

The DOF is defined as the number of comparisons between machining parameters that need to be made to determine, which level is better and specifically how much better it is. As per Taguchi experimental design philosophy a set of three levels assigned to each process parameters has two degrees of freedom (DOF) and for two level process parameters one degrees of freedom. This gives a total of $9 \mathrm{DOF}$ for five process parameters selected in this work. Taguchi L18 orthogonal array is used as shown in the Table 3.2

Table 3.1: Process parameters and their levels

\begin{tabular}{|c|c|c|c|c|c|}
\hline Factors & Parameters & Units & L1 & L2 & L3 \\
\hline A & $\begin{array}{c}\text { Cutting } \\
\text { environment }\end{array}$ & & Wet & Dry & \\
\hline B & Cutting speed & $\mathrm{m} / \mathrm{min}$ & 55 & 75 & 95 \\
\hline C & Feed rate & $\mathrm{mm} / \mathrm{rev}$ & 0.15 & 0.25 & 0.35 \\
\hline D & Depth of cut & $\mathrm{Mm}$ & 0.10 & 0.15 & 0.20 \\
\hline E & Nose radius & $\mathrm{Mm}$ & 0.3 & 0.4 & 0.5 \\
\hline
\end{tabular}

Table 3.2: L18 orthogonal array for present work

\begin{tabular}{|l|l|l|l|l|l|}
\hline & 1 & 2 & 3 & 4 & 5 \\
\hline
\end{tabular}


International Journal of Design and Manufacturing Technology (IJDMT), ISSN 0976 - 6995(Print), ISSN 0976 - 7002(Online) Volume 4, Issue 3, September - December (2013), ( ) IAEME

\begin{tabular}{|c|c|c|c|c|c|}
\hline $\begin{array}{c}\text { Trail } \\
\text { No. }\end{array}$ & A & B & C & D & E \\
\hline 1 & Wet & 55 & 0.15 & 0.10 & 0.30 \\
\hline 2 & Wet & 55 & 0.25 & 0.15 & 0.40 \\
\hline 3 & Wet & 55 & 0.35 & 0.20 & 0.50 \\
\hline 4 & Wet & 75 & 0.15 & 0.10 & 0.40 \\
\hline 5 & Wet & 75 & 0.25 & 0.15 & 0.50 \\
\hline 6 & Wet & 75 & 0.35 & 0.20 & 0.30 \\
\hline 7 & Wet & 95 & 0.15 & 0.15 & 0.30 \\
\hline 8 & Wet & 95 & 0.25 & 0.20 & 0.40 \\
\hline 9 & Wet & 95 & 0.35 & 0.10 & 0.50 \\
\hline 10 & Dry & 55 & 0.15 & 0.20 & 0.50 \\
\hline 11 & Dry & 55 & 0.25 & 0.15 & 0.30 \\
\hline 12 & Dry & 55 & 0.35 & 0.10 & 0.40 \\
\hline 13 & Dry & 75 & 0.15 & 0.15 & 0.50 \\
\hline 14 & Dry & 75 & 0.25 & 0.20 & 0.30 \\
\hline 15 & Dry & 75 & 0.35 & 0.10 & 0.40 \\
\hline 16 & Dry & 95 & 0.15 & 0.20 & 0.40 \\
\hline 17 & Dry & 95 & 0.25 & 0.10 & 0.50 \\
\hline 18 & Dry & 95 & 0.35 & 0.15 & 0.30 \\
\hline
\end{tabular}

\subsection{EXPERIMENTAL DETAILS}

\subsection{Work material}

The work piece material selected for the study was Ti-6Al-4V ELI. It is the Grade 23 Titanium alloy material. It has high strength, high quality surface finish, advanced corrosion resistances and excellent biocompatibility. The size of the workpiece was $25 \mathrm{~mm}$ diameter and $300 \mathrm{~mm}$ length. One millimeter thickness of workpiece material at the top surface of workpiece was removed in order to eliminate any surface defects and residuals stress that can adversely affect the machining result (8). The chemical compositions and mechanical properties of workpiece materials are given in Table 4.1 and Table 4.2

Table 4.1: Chemical composition of the workpiece materials Ti-6Al-4V ELI (wt\%)

\begin{tabular}{|c|c|c|c|c|c|c|c|c|c|c|c|}
\hline Type & $\mathrm{N}$ & $\mathrm{H}$ & $\mathrm{Fe}$ & $\mathrm{O}$ & $\mathrm{V}$ & $\mathrm{Al}$ & $\mathrm{Ti}$ & $\mathrm{Y}$ & $\mathrm{Si}$ & $\mathrm{C}$ & $\mathrm{S}$ \\
\hline $\begin{array}{c}\mathrm{C}- \\
11465\end{array}$ & 0.007 & 0.0031 & 0.18 & 0.13 & 4 & 6.1 & bal & $<0.005$ & $<0.03$ & 0.11 & $<0.003$ \\
\hline
\end{tabular}

Table 4.2: Mechanical properties of Ti-6Al-4V ELI

\begin{tabular}{|c|c|c|c|}
\hline Tensile $(\mathrm{KPa})$ & $2 \%$ yield $(\mathrm{KPa})$ & 4D \% Elong ED & RA \% \\
\hline 910108 & 820476 & $17.0 / 14.0$ & 42.0 \\
\hline
\end{tabular}


International Journal of Design and Manufacturing Technology (IJDMT), ISSN 0976 - 6995(Print), ISSN 0976 - 7002(Online) Volume 4, Issue 3, September - December (2013), () IAEME

\subsection{Selection of cutting tool and tool holder}

The cutting tool and the tool holder for the machining of Ti-6Al-4V ELI was recommended by the tool supplier. The KC5010 tool consists of layer of TiAlN. The tool geometry of the insert is as follows

Insert shape

Insert clearance angle

Cutting edge length

Nose radius
$: 80^{\circ}$ triangle

$: 7^{\circ}$

$: 12.9 \mathrm{~mm}$

$: 0.2 \mathrm{~mm}$

\subsection{Experimental plan}

Cutting tests were carried out on CNC lathe machine under wet and dry conditions. The machining process on CNC lathe is programmed by speed, feed and depth of cut.

Surface roughness can generally be described as the geometric features of the surface. Surface roughness measurement is carried out by using a portable stylus profilometer. Surface roughness being a lower the better type of machining quality characteristics the $\mathrm{S} / \mathrm{N}$ ratio for this type of response was used and given below (9).

$\mathrm{S} / \mathrm{N}$ ratio $=-10 \log _{10}\left[\mathrm{Y}_{1}^{2}+\mathrm{Y}_{2}^{2}+\ldots \ldots+\mathrm{Y}_{\mathrm{n}}^{2}\right] / \mathrm{N} \quad$ Eq.2

Where $\mathrm{Y} 1, \mathrm{Y} 2 \ldots \mathrm{Yn}$ are the response of the machining characteristic for a trial condition repeated $n$ times.

Table 4.3: The $\mathrm{S} / \mathrm{N}$ ratio compute using Eq.2 for each 18 trials and the value are reported

\begin{tabular}{|c|c|c|c|}
\hline Trial no. & $\mathrm{R} 1(\mu \mathrm{m})$ & $\mathrm{R} 2(\mu \mathrm{m})$ & S/N Ratio \\
\hline 1 & 4.02 & 3.96 & -12.019 \\
\hline 2 & 2.80 & 2.83 & -8.989 \\
\hline 3 & 2.66 & 2.67 & -8.513 \\
\hline 4 & 1.96 & 2.06 & -9.076 \\
\hline 5 & 1.96 & 1.89 & -5.690 \\
\hline 6 & 5.12 & 4.92 & -14.015 \\
\hline 7 & 3.27 & 3.28 & -10.304 \\
\hline 8 & 2.98 & 2.96 & -9.455 \\
\hline 9 & 2.82 & 2.76 & -8.912 \\
\hline 10 & 1.24 & 1.27 & -1.973 \\
\hline 11 & 6.42 & 6.26 & -16.04 \\
\hline 12 & 3.91 & 3.86 & -11.788 \\
\hline 13 & 1.21 & 1.18 & -1.548 \\
\hline 14 & 5.38 & 5.45 & -14.672 \\
\hline 15 & 3.97 & 3.91 & -11.910 \\
\hline 16 & 2.04 & 2.14 & -6.405 \\
\hline 17 & 1.91 & 1.86 & $-5 . .506$ \\
\hline 18 & 3.92 & 3.98 & -11.932 \\
\hline
\end{tabular}


International Journal of Design and Manufacturing Technology (IJDMT), ISSN 0976 - 6995(Print), ISSN 0976 - 7002(Online) Volume 4, Issue 3, September - December (2013), ( ) IAEME

Table 4.4: ANOVA for Surface Roughness

\begin{tabular}{|c|c|c|c|c|c|}
\hline Source & DF & SS & MS & F & \%P \\
\hline CE & 1 & 1.506 & 1.506 & 0.479 & 0.54 \\
\hline V & 2 & 3.976 & 1.988 & 0.633 & 1.44 \\
\hline F & 2 & 59.138 & 29.564 & 9.416 & 21.49 \\
\hline DOC & 2 & 2.221 & 1.1105 & 0.3536 & 0.81 \\
\hline NR & 2 & 183.309 & 91.654 & 29.189 & 66.59 \\
\hline Error & 8 & 25.119 & 3.139 & & 9.125 \\
\hline Total & 17 & 275.27 & & & \\
\hline
\end{tabular}

Table 4.5: Response table for surface roughness

\begin{tabular}{|c|c|c|c|c|c|}
\hline LEVEL & CE & V & F & DOC & NR \\
\hline 1 & 9.663 & 9.887 & 6.893 & 9.868 & 13.163 \\
\hline 2 & 9.086 & 9.485 & 10.058 & 9.083 & 9.6038 \\
\hline 3 & & 8.752 & 11.172 & 9.172 & 5.357 \\
\hline Delta & 0.577 & 1.135 & 4.279 & 0.785 & 7.806 \\
\hline Rank & 5 & 3 & 2 & 4 & 1 \\
\hline
\end{tabular}

The ranks indicate the relative importance of each factor to the response. The ranks and the delta values for the various parameters show that nose radius has the greatest effect on surface roughness and is followed by feed, cutting speed, depth of cut and coolant condition in that order. As surface roughness is the lower the better type quality characteristic, from table 4.5 , it can be seen that the first level of coolant condition (A1), third level of cutting speed (B3), first level of feed (C1), second level of depth of cut(D2) and third level of nose radius (E3) result in minimum value of surface roughness.

\subsection{CONCLUSION}

Based on the results obtained, the following conclusions can be drawn

1. Analysis of variance suggest the nose radius is most significant factor for surface roughness

2. ANOVA (S/N data) results shows that nose radius, feed rate, cutting speed, depth of cut and coolant condition affects the surface roughness by $65.54 \%, 21.48 \%, 1.44 \%$, $0.80 \%, 0.54 \%$ respectively

\section{REFERENCES}

[1] H.K.Dave, L.S.Patel and H.K.Raval, Effect of machining conditions on MRR and surface roughness during CNC Turning of different materials using TiN Coated Cutting Tools - A Taguchi approach, International Journal of Industrial Engineering Computations, 3 (2012)

[2] A.Yildiz, F.Ozturk, Hybrid enhanced genetic algorithm to select optimal machining parameters in turning operation, Mechanical Engineering Department, Vol 220, 2006, pp. $2041-2053$.

[3] Pinkey, Kusum, Millie, Optimizing CNC Turning Process using real Coded genetic algorithm and differential evolution, Global Journal of Technology and Optimization, Vol 2, 2011. 
[4] T.Srikanth, V.Kamala, A Real Coded Genetic Algorithm for Opimization of cutting parameters in turning, UCSNS International Journal of Computer Science and Network Security, Vol 8, 2008, pp.189-193.

[5] F.Klocke, G.Eisenblatter, Dry cutting, Ann. CIRP 46 (2) (1997), pp. 519-526.

[6] Saad Kariem Shather. 2009. Studying the effect of tool nose radius on workpiece runout and surface finish. Engineering and technology journal. 27 (2), pp 256- 261.

[7] Gursheng Su, wear characteristics of nano TiAlN coated carbide tools in ultra high speed machining of AerMet 100s, Wear,2012, pp 124- 131.

[8] Kalpakjian S and S R Rahmid,Manufacturing engineering and technology, $4^{\text {th }}$ edition, prentice hall, 2001.

[9] Ranjit roy, A primer on taguchi method, Van Nostrand Reinhold, New York, 1990.

[10] k. krishnaiah, P. Shahabudeen, Applied design of experiments and taguchi methods, PHI learning private limited, 2012.

[11] M.Chithirai Pon Selvan and Dr.N.Mohanasundara Raju, "Modeling and Analysis of Depth of Cut in Abrasive Waterjet Cutting of Titanium", International Journal of Mechanical Engineering \& Technology (IJMET), Volume 2, Issue 2, 2011, pp. 39 - 46, ISSN Print: 0976 - 6340, ISSN Online: 0976 - 6359.

[12] Prabhat Kumar Sinha, Manas Tiwari, Piyush Pandey and Vijay Kumar, "Optimization of Input Parameters of CNC Turning Operation for the Given Component using Taguchi Approach", International Journal of Mechanical Engineering \& Technology (IJMET), Volume 4, Issue 4, 2013, pp. 188 - 196, ISSN Print: 0976-6340, ISSN Online: $0976-6359$.

[13] Prof. (Dr). Rachayya.R.Arakerimath and Prof (Dr).V.A.Raikar, "Productivity Improvement by Sa and Ga Based Multi-Objective Optimization in CNC Machining", International Journal of Mechanical Engineering \& Technology (IJMET), Volume 3, Issue 1, 2012, pp. 100 - 109, ISSN Print: 0976 - 6340, ISSN Online: 0976 - 6359.

[14] Ganesan.H and Mohankumar.G, "Study on Optimization of Machining Parameters in Turning Process using Evolutionary Algorithm with Experimental Verification", International Journal of Mechanical Engineering \& Technology (IJMET), Volume 2, Issue 1, 2011, pp. 10 - 21, ISSN Print: 0976 - 6340, ISSN Online: 0976 - 6359.

[15] Nitin Sharma, Shahzad Ahmad, Zahid A. Khan and Arshad Noor Siddiquee, "Optimization of Cutting Parameters for Surface Roughness in Turning", International Journal of Advanced Research in Engineering \& Technology (IJARET), Volume 3, Issue 1, 2012, pp. 86 - 96, ISSN Print: 0976-6480, ISSN Online: 0976-6499, Published by IAEME. 